\title{
SENSIBILIZAÇÃO DE AGENTES MULTIPLICADORES PARA O DESENVOLVIMENTO DE PROJETOS AMBIENTAIS COMUNITÁRIOS, NO MUNICÍPIO DE AGUDO/RS
}

\author{
Cláudia Bernardini' ${ }^{1}$ Vânia Medianeira Flores da Costa² \\ 1- Aluna do curso de Especialização em Educação Ambiental da UFSM, Autora, claudia.ambiente@hotmail.com \\ 2- Professora Dra. do Curso de Especialização em Educação Ambiental da UFSM. Orientadora, \\ vaniaflores2006@yahoo.com.br
}

Palavras-chave: educação ambiental; sensibilização; ações comunitárias

O presente estudo teve como objetivo principal sensibilizar os agentes multiplicadores para o desenvolvimento de ações comunitárias para melhoria da qualidade ambiental local. Partiu da premissa de que a participação e o envolvimento das lideranças de grupos organizados são fundamentais para se mudar uma realidade que não condiz com as necessidades de qualidade de vida, perpassando por aspectos relevantes da qualidade ambiental local. Foram realizadas ações para sensibilizar e motivar lideranças comunitárias do Município de Agudo a agirem como multiplicadores de ações práticas que melhorassem a qualidade ambiental do espaço comunitário a que estavam atreladas. Dentre as práticas cita-se a realização do seminário municipal para sensibilização, em julho de 2009, durante as atividades da Semana do Meio Ambiente de Agudo, onde na ocasião, trabalhou-se a aplicação da ferramenta $5 \mathrm{~W} 2 \mathrm{H}$ para facilitar o planejamento das ações comunitárias que foram propostas pelas lideranças após diagnóstico das necessidades locais no âmbito dos problemas ambientais. Posteriormente foram realizadas visitas técnicas, de orientação e acompanhamento, bem como a divulgação dos resultados na mídia local. Cabe salientar que, neste estudo, a educação ambiental é entendida como os processos pelos quais ocorrem mudanças internas nos seres humanos culminando com novas atitudes que garantam a sustentabilidade da vida humana, o que propiciou aos participantes a oportunidade de posicionarem-se como reais agentes de mudança de sua realidade. Ao final, conseguiu-se a realização efetiva de 15 (quinze) das 26 (vinte e cinco) ações propostas, sendo que 4 foram realizadas de forma incompleta. Considerou-se um resultado positivo, visto que, somente 2 comunidades não realizaram nenhuma ação. Nas demais, ao menos uma proposta foi concluída, o que certamente gerou movimento de mais lideranças ou participantes na sua realização, efetivando o conceito de multiplicadores àqueles que propuseram inicialmente os projetos.

\section{Introdução}

A preservação do meio ambiente perpassa por atitudes pequenas e individuais. Ao longo do tempo vem sendo desenvolvidos diversos trabalhos em educação ambiental focados a alunos, tendo a esperança de que estes levarão a seus pais algumas informações que os sensibilizem para a preservação e proteção ambiental. Percebe-se, no entanto, um distanciamento entre as ações desenvolvidas nas escolas, que muitas vezes ficam restritas à sala de aula, e as atividades que acontecem no meio em que as crianças e professores vivem (MININNI-MEDINA, 2001). 
Entende-se que o trabalho de educação ambiental como uma das principais ferramentas para buscar o envolvimento de mais pessoas na causa ambiental. As atividades precisam despertar a sensibilidade de um número ainda maior de pessoas, através da participação em atividades que condizem com a realidade em que vivem; fazendo com que passem a olhar o mundo ao seu redor com olhos de admiração e respeito, gerando atitudes preservacionistas, com um olhar sócio ambiental (ROSA, 2001).

É de importante que toda e qualquer ação seja valorizada, disseminada e divulgada como forma de motivar àqueles que estão envolvidos na causa. No entanto, pergunta-se como sensibilizar lideranças comunitárias a perceberem questões ambientais a serem melhoradas em seus locais de atuação e motivarem-se a realizar projetos/ações ambientais para qualificar esse ambiente?

Agudo é um Município que possui histórico de desenvolvimento de projetos ambientais, principalmente por iniciativa das escolas, do poder público e de entidades como a Associação Riograndense de Empreendimentos e de Assistência Técnica e Extensão Rural (EMATER/RS-ASCAR) e Sociedade Ecológica Amigos do Jacuí (Sejamigo). Considera-se um marco inicial, o Projeto de Educação Ambiental da Quarta Colônia, realizado pelo Consórcio de Desenvolvimento Sustentável da Quarta Colônia (CONDESUS) no ano de 1999.

De acordo com informações obtidas na Secretaria da Agricultura e Meio Ambiente, com a gestão ambiental municipalizada em 2002, através da Resolução do Conselho Estadual do Meio Ambiente (CONSEMA) n o 025/2002, Agudo passou a ter um Conselho Municipal de Defesa do Meio Ambiente, com membros de entidades governamentais e não governamentais representativas na comunidade, bem como um Departamento de Meio Ambiente atrelado à Secretaria da Agricultura, que passou a ser chamada de Secretaria da Agricultura e Meio Ambiente.

Nesse sentido percebe-se um avanço nas iniciativas em gestão e educação ambiental, iniciando com o fortalecimento de um projeto iniciado pela EMATER/RS-ASCAR, em 2000, que é a coleta de lixo no meio rural. Conforme relato da Veterinária Nara Pedroso, da Vigilância Sanitária da Prefeitura de Agudo, foram realizadas reuniões em todas as localidades que possuíam igreja, cemitério e/ou centros comunitários, onde foram abordados aspectos sobre tipos de lixo gerados e a destinação correta, bem como a busca do comprometimento das comunidades em ter um local específico para o armazenamento dos resíduos provenientes das atividades em centros comunitários e dos resíduos das flores e vasos dos cemitérios. Houve também o apelo para que cada um, em sua residência, armazenasse o lixo seco, pois a Prefeitura realizaria a coleta a cada dois meses (projeto este que existe até hoje).

Deste trabalho nasceu a "Operação Agudo Limpo", que teve sua primeira edição no ano de 2006, onde todas as escolas foram conclamadas a parar suas atividades formais e montar equipes de trabalho com a comunidade escolar envolvida, e promover o recolhimento de lixo nos mananciais hídricos, centros comunitários, beiras de estrada, paradas de ônibus. Os alunos e a comunidade em geral foram motivados a realizar grandes faxinas também em suas casas. $\mathrm{Na}$ primeira Operação Agudo Limpo foram recolhidas 27 caçambas de lixo. A partir da segunda edição, somente uma escola continuou com a proposta das equipes e esta, até este ano, envolve 40 grupos em toda sua área de abrangência. Nos demais locais a mobilização acontece sem o envolvimento e coordenação das escolas (BERNARDINI, 2006). Conforme informações do Departamento de Meio Ambiente, nas duas últimas edições houve envolvimento de empresas locais no auxílio ao recolhimento do material. Devido ao trabalho semanal de coleta de lixo no 
interior, feito pela Prefeitura, as cargas diminuíram para 11 e 15, na segunda e terceira Operação (BERNARDINI,2007 e 2008).

Conforme equipe do Departamento de Meio Ambiente de Agudo, há preocupação constante com a busca de soluções para a destinação de resíduos especiais no Município. Destacam-se assim, algumas ações importantes que foram realizadas. Em 2006, tendo motivação na realização da Copa do Mundo de Futebol e o sentimento de nacionalidade reinante, foi lançada a Campanha de Recolhimento de Pneus, onde o Departamento de Meio Ambiente, com apoio de recursos do Fundo Municipal de Meio Ambiente, adquiriu bolas, bandeiras, faixas e chaveiros com motivos da bandeira nacional, e distribuiu entre os alunos da rede pública e privada municipal e estadual, conforme a quantidade de pneumáticos recolhida. Este passivo ambiental foi destinado a uma empresa recicladora e até hoje a Prefeitura recolhe mensalmente os pneus das borracharias da cidade e do interior e os leva a uma recicladora de Canoas/RS (BERNARDINI,2006).

Em 2008 iniciou-se a Campanha de Recolhimento de Eletroeletrônicos, elas acontecem anualmente ou a cada 6 meses e são uma referência para a população e comércio, como sendo a melhor alternativa de destinação final de equipamentos elétricos e eletrônicos, já que a Prefeitura os encaminha a uma recicladora de Porto Alegre/RS.

No ano seguinte, com recursos do Fundo do Meio Ambiente, foi paga a reciclagem de 1.677 lâmpadas fluorescentes, acabando com um passivo ambiental de muitos anos (BERNARDINI 2009). Hoje há envolvimento da Promotoria de Justiça na busca de soluções para a coleta reversa, conforme prevê a Lei Estadual no 11.019, de 23 de setembro de 1997.

A EMATER/RS-ASCAR e Departamento de Meio Ambiente realizaram no ano de 2006, o Fórum Municipal da Água, que aconteceu durante a Semana Interamericana da Água, no mês de outubro. Para Adriana Goltz, extensionista rural da EMATER/RS - ASCAR, ações como a obrigatoriedade de lixeiras nos ônibus do transporte escolar, qualificação dos roteiros de coleta de lixo no interior, projeto de proteção e drenagem de fontes superficiais (PROAGUA), foram realizados motivados pelos diagnósticos de problemas ambientais levantados no Fórum (BERNARDINI, 2006)

A SEJAMIGO realiza passeios ecológicos via Rio Jacuí, onde são retiradas toneladas de lixo do leito e margens. Segundo relato do presidente Renato Pacheco, desde que a entidade foi criada, em 2005, desenvolve esse tipo de ação, percebe-se uma diminuição considerável no lixo disposto no rio. A SEJAMIGO entende que as coletas de lixo no meio rural, campanhas "Operação Agudo Limpo", bem como o trabalho contínuo realizado pelas escolas e meios de comunicação para a conscientização da população, estão contribuindo para essa melhora. Outro ponto positivo são as coletas de embalagens de agrotóxicos realizadas duas vezes ao ano pela Cooperativa de Agudo e pelas empresas fumageiras que atuam no município. Os técnicos da cooperativa dizem que não houve significativo aumento nas vendas de agrotóxicos, mas há aumento expressivo na devolução das embalagens, o que faz acreditar que os produtores estão mais conscientes.

Nesse contexto histórico de projetos ambientais desenvolvidos, e tendo em vista a bagagem teórica trazida aos munícipes de Agudo sobre questões que envolvam o meio ambiente em função desses projetos, resolveu-se propor um trabalho de sensibilização dos agentes multiplicadores para o desenvolvimento de ações comunitárias para melhoria da qualidade ambiental local. Se não bastasse o entendimento puro e simples que supostamente um educador ambiental deve ter sobre sua responsabilidade em promover a educação ambiental em diversos níveis, quando se está inserido em um serviço público onde as questões ambientais permeiam diretamente o trabalho diário, a responsabilidade intrínseca é maior. A Constituição Federal 
(p.139, 1988), em seu Capítulo VI, Artigo 225, fala sobre o direito de todos a um meio ambiente equilibrado, importante à qualidade de vida das pessoas, e impõe ao Poder Público e à sociedade o dever de defendê-lo e preservá-lo. Especificamente no $\S 1$ 1․ ÍTEM VI, do mesmo artigo, a lei incumbe ao Poder Público a promoção da "educação ambiental em todos os níveis de ensino e a conscientização pública para a preservação do meio ambiente." A Lei 9.795/99, que institui a Política Nacional de Educação Ambiental (MULLER, 2001, p.379), em seu artigo 3으, diz que todos têm direito à educação ambiental, sendo que o INCISO I incumbe "ao Poder Público, nos termos dos arts. 205 e 225 da Constituição Federal, definir políticas públicas que incorporem a dimensão ambiental, promover a educação ambiental em todos os níveis de ensino e o engajamento da sociedade na conservação, recuperação e melhoria do meio ambiente;". Assim, a ação de sensibilização proposta neste projeto, se enquadra como uma ferramenta também de cumprimento legal, já que é desenvolvida dentro e pelo Departamento de Meio Ambiente da Prefeitura de Agudo.

Com base na legislação citada entendeu-se que a criação de um espaço específico de encontro de lideranças para diagnosticar realidades e propor ações para resolução de problemas, seria um meio de se fazer educação ambiental não-formal com uma sociedade que é, junto com o poder público proponente, a co-responsável pelas ações preservacionistas que se espera como uma forma de melhoria ambiental.

\section{METODOLOGIA}

O presente projeto caracteriza-se metodologicamente como uma pesquisa-ação, visto que, juntamente com o diagnóstico de problemas específicos, imediatamente procura uma prática para atingir resultados. Possui caráter auto-avaliativo, pois no decorrer dos processos as práticas vão sendo monitoradas e modificadas caso haja necessidade, conforme a interação entre os atores envolvidos (SILVA e MENEZES, 2001).

O público-alvo foi lideranças de grupos/sociedades/associações organizadas do Município de Agudo, vistas nesse projeto como possíveis multiplicadores de atitudes ambientais preservacionistas dentro de suas comunidades de ação. O local onde foi desenvolvido o projeto, Município de Agudo, tem um histórico de desenvolvimento de trabalhos em meio ambiente por parte do poder público e iniciativa privada, como já foi relatado na introdução deste trabalho.

Como forma de reunir as lideranças, apresentar o projeto e de imediato desenvolver atividades de sensibilização, em 21 de julho de 2009 organizou-se o I Seminário Ambiental para Multiplicadores, com parceria da EMATER/RS-ASCAR, (escritório Agudo) onde foram enviados em torno de 40 (quarenta) convites à equipe diretiva das escolas de Agudo, ACPM's (Associação Círculo de Pais e Mestres), grupos de jovens, grupos de trabalhadoras rurais, grupos de famílias, sociedades, clubes de serviço, associações comunitárias e comunidades religiosas. Atenderam ao chamado os representantes de todos os segmentos, perfazendo um total de 23 lideranças.

Com a realização da palestra, com a psicóloga Jonice da Silveira, buscou-se a sensibilização perante os problemas ambientais e tomada de consciência e atitude levando em conta a responsabilidade da sociedade organizada com o bem estar e a qualidade de vida das pessoas (que envolve a necessidade de um ambiente natural equilibrado). 
Num segundo momento, a organização do evento, composta pelo Departamento de Meio Ambiente e EMATER/RS-ASCAR, agrupou os presentes conforme afinidades geográficas de suas entidades representativas (entidades de localidades próximas ou grupos que utilizavam o mesmo espaço físico para suas reuniões, encontros e eventos). Assim, houve formação de equipes de trabalho que, conforme a proposta da organização, discutiram os principais problemas e suas conseqüências ambientais ocorridos em nível de espaço físico comunitário, bem como a prática que poderia ser adotada para minimizar os danos ou trazer bem estar e qualidade de vida a quem utiliza desse espaço.

Periard (2009) apresenta a ferramenta 5W2H e sua forma de utilização, foi disponibilizado aos grupos cópia da mesma para que montassem seu Plano de Trabalho. Segundo o autor, a ferramenta 5W2H é utilizada para melhor organização do planejamento de ações, já que em uma tabela, é descrita a ação a ser realizada e em função desta são respondidas as seguintes perguntas: What? (o que será feito), Who? (quem fará),When? (quando será feito), Where? (onde será feito), Why? (por que será feito), How? (como será feito), How Much? (quanto custará) - na tabela apresentada aos grupos foram utilizadas somente as expressões em português. As lideranças retornaram às suas comunidades e preencheram o Plano de Trabalho com mais calma, mas foi pedido que atentassem para que, ao realizar a ação planejada, pudessem envolver o maior número possível de pessoas, no intuito de socializar e disseminar as práticas. A empresa EMATER/RS-ASCAR e a Secretaria da Agricultura e Meio Ambiente colocaram-se à disposição para orientações técnicas caso houvesse necessidade.

Atendendo o objetivo de construir um banco de dados com as informações relevantes sobre o planejamento das ações, montou-se um quadro de controle e acompanhamento conforme consta na descrição dos resultados. A partir daí foram feitas visitas (ou por pedido da comunidade ou para acompanhamento da equipe organizadora do projeto) no intuito de acompanhar as ações. Posteriormente foram realizadas entrevistas para quantificar os resultados e para que as lideranças avaliassem o desenvolvimento deste projeto. O espaço para os grupos apresentarem o resultado de suas ações aconteceu na programação da Semana do Meio Ambiente de Agudo/2010, durante o II Seminário Ambiental, bem como na mídia impressa local.

\section{RESULTADOS E DISCUSSÕES}

A forma de apresentação dos resultados, no intuito de melhor visualizar o contexto em que se encontram as informações, é apresentada por meio dos quadros 1, 2 e 3. Neles estão descritos os levantamentos quanto à participação de lideranças comunitárias (quais lideranças e de quais comunidades) no projeto, bem como o diagnóstico das realidades e necessidades locais de melhorias ambientais. Posteriormente, também em quadro, apresenta-se a evolução das ações locais com a opinião das lideranças sobre as dificuldades encontradas, motivação comunitária e satisfação pessoal com os resultados obtidos. São também analisados, por parte da coordenação geral do projeto, dados quantitativos referentes aos resultados obtidos e a percepção quanto ao envolvimento das lideranças no desenvolvimento do projeto.

Inicialmente, a formação dos grupos de lideranças com afinidades geográficas de suas entidades representativas gerou discussões que culminaram no diagnóstico da realidade local em 
relação a problemas ambientais no contexto comunitário e posteriormente em propostas de ações (Quadro 1).

Quadro 1. Comunidades, lideranças e ações ambientais propostas.

\begin{tabular}{|c|c|c|c|}
\hline GRUPO & ORGANIZAÇÕES & REPRESENTANTE & PROPOSTA \\
\hline \multirow[t]{3}{*}{$\begin{array}{l}1 \quad-\quad \text { Linha } \\
\text { Teotônia e Linha } \\
\text { dos Pomeranos }\end{array}$} & $\begin{array}{l}\text { CASCATA RADDATZ } \\
\text { COMUNIDADE ROLF PACHALY }\end{array}$ & Valdino Vitalis & $\begin{array}{l}\text { Proteção de Fontes. } \\
\text { Construção de pocilgas. } \\
\text { Construção de Cisterna. }\end{array}$ \\
\hline & \begin{tabular}{ll|} 
COMUNIDADE & BENTO \\
GONÇALVES & \\
\end{tabular} & Markendorf & Sumidouro. \\
\hline & E. STO ANTONIO & Anilson da Silva & $\begin{array}{l}\text { Lixeiras na Comunidade. } \\
\text { Melhoria nos depósitos de água. }\end{array}$ \\
\hline \multirow[t]{3}{*}{ 2- Linha Boêmia } & SOCIEDADE FARROUPILHA & Luismar Neuendfeldt & $\begin{array}{l}\text { Fossa, Sumidouro - } \\
\text { Lixeiras no Pavilhão e cemitério. } \\
\text { Plantio de árvores no Pavilhão. }\end{array}$ \\
\hline & COMUNIDADE SÃO MARCOS & Eno Neu & $\begin{array}{l}\text { Lixeiras no pavilhão e Cemitério } \\
\text { Destino das águas servidas }\end{array}$ \\
\hline & COMUNIDADE SANTA LUZIA & Celi Raddatz & Lixeiras no pavilhão e Cemitério. \\
\hline 3- Porto Alves & SOCIEDADE PORTO ALVES & $\begin{array}{l}\text { Guilherme Schwede } \\
\text { Hilberto Bock } \\
\text { Magdiel Dickow }\end{array}$ & $\begin{array}{l}\text { Colocação de lixeiras e destino } \\
\text { dos esgotos geral. }\end{array}$ \\
\hline 4 - Cidade & $\begin{array}{l}\text { GRUPO TURISMO } \\
\text { EMATER } \\
\text { E. SANTOS DUMONT } \\
\text { E. WILLY ROOS } \\
\text { E. D. PEDRO II } \\
\text { CONDEMA/GRUPO CERRO } \\
\text { CHATO }\end{array}$ & $\begin{array}{l}\text { Nelson Dias } \\
\text { Marciano Filho } \\
\text { Prof Hildo Friedrich } \\
\text { Profa Fabiane Boeck } \\
\text { Prof Janete Boeck } \\
\text { Prof. Taise hoppe } \\
\text { Celi Behrenz }\end{array}$ & Arborização urbana \\
\hline
\end{tabular}


Monografias Ambientais

(e-ISSN: 2236-1308)

\begin{tabular}{|c|c|c|c|}
\hline 5 - Nova Boêmia & $\begin{array}{l}\text { E. OLAVO BILAC } \\
\text { GRUPO SOL NASCENTE } \\
\text { COMUNIDADE EVANGÉLICA }\end{array}$ & $\begin{array}{l}\text { Prof Olívio de Souza } \\
\text { Prof Dieter Streck } \\
\text { Profa Josiane Rossato } \\
\text { Ivone Angélica } \\
\text { Gilsomar Kegler }\end{array}$ & $\begin{array}{l}\text { Construção de depósito de lixo na } \\
\text { escola e comunidade para } \\
\text { posterior coleta. } \\
\text { Canalizar esgotos da Escola. } \\
\begin{array}{l}\text { Manejo da criação de suínos em } \\
\text { propriedade ao lado da escola }\end{array}\end{array}$ \\
\hline $\begin{array}{l}6 \text { - Várzea do } \\
\text { Agudo }\end{array}$ & GRUPO AMIZADE & Izônia Gehrke & $\begin{array}{|lr|}\text { Colocação de lixeiras na } \\
\text { Sociedade União e no cemitério } \\
\text { da localidade. }\end{array}$ \\
\hline $\begin{array}{l}7 \text {-Rincão do } \\
\text { Pinhal }\end{array}$ & $\begin{array}{l}\text { SEJAMIGO } \\
\text { ATRA/ GRUPO ESPERANÇA } \\
\text { GRUPO RENASCER } \\
\text { COMUNIDADE } \\
\text { CONGREGACIONAL }\end{array}$ & $\begin{array}{l}\text { Renato Pacheco } \\
\text { Elaine Soares } \\
\text { Loane Zimmer } \\
\text { Lauri Horbe }\end{array}$ & $\begin{array}{l}\text { Sumidouro na Com São José - } \\
\text { Rincão do Pinhal. } \\
\text { Embelezamento do Cemitério de } \\
\text { Rincão do Pinhal } \\
\begin{array}{l}\text { Colocação de Lixeiras na } \\
\text { comunidade São José. }\end{array}\end{array}$ \\
\hline
\end{tabular}

Após o Seminário Ambiental, os grupos mantiveram contatos com a coordenação do projeto. Em agosto de 2009 houve pedido da Sociedade de Famílias Bento Gonçalves, localidade de Linha Teotônia, para que houvesse orientação aos associados, sobre a proposta feita aos grupos. Na reunião com as famílias foi apresentado o objetivo do projeto maior e a necessidade de comprometimento daquela organização para atingir a meta de qualificação da destinação dos esgotos, proposta pelo presidente, que identificou como sendo este o principal problema encontrado no centro comunitário utilizado pela Sociedade. Foi distribuído modelo de planta com a destinação correta dos esgotos e águas servidas utilizada pela EMATER/RS-ASCAR em seus trabalhos de extensão rural. Houve manifestação sobre a necessidade do apoio do Poder Público Municipal, através da Secretaria de Obras, com doação de horas/máquina para facilitar a abertura de estruturas para abrigar fossa e sumidouro. Esse pedido motivou a abordagem do Secretário, por meio de diálogo e oficialização do pedido no memorando do Departamento de Meio Ambiente, que garantiu prioridade das máquinas para os serviços comunitários vinculados a este projeto.

Veiculou-se notícias no programa da Prefeitura de Agudo na rádio AM local, visando lembrar as comunidades e lideranças dos compromissos assumidos. No mês de janeiro de 2009, o Grupo de Jovens Força Jovem, da Linha dos Pomeranos, que não havia participado do I Seminário Ambiental para Multiplicadores, solicitou que fosse incluído para realização de algumas práticas ambientais em sua comunidade, também em virtude de estarem comemorando 25 anos de fundação. Para esse caso, foi montado em conjunto com a EMATER/RS-ASCAR um planejamento maior, sendo realizada uma gincana cultural, esportiva e ambiental que, sob o ponto de vista ambiental, teve seu ápice na realização do Seminário Ambiental 2010, pela primeira vez sediado no interior do Município. Ao grupo foram propostas atividades de levantamento fotográfico do "antes e depois" das paisagens naturais serranas, para acompanhar a evolução da ocupação humana, plantio de árvores na sede do grupo e paródia ambiental com apresentação da música 
utilizando equipamentos sonoros feitos com material reciclável. Todas as tarefas foram concluídas até o mês de junho.

No mês de fevereiro e posteriormente em maio, foram realizadas visitas para verificação do andamento das ações e da disponibilização de auxílio se alguém estivesse com dificuldades. A maioria dos projetos não havia sequer sido iniciada e outros estavam em fase intermediária de conclusão. Outro objetivo era o convite às organizações para realizarem o relato das ações implementadas no Seminário de Meio Ambiente, dia 02 de junho de 2010, durante a Semana do Meio Ambiente de Agudo. Como algumas não executaram nada do que haviam proposto e outras somente parcialmente, foram realizadas entrevistas para verificar os motivos deste resultado (Quadro 2).

\begin{tabular}{|c|c|c|}
\hline ORGANIZAÇÕES & PROPOSTA & Motivo da não realização das ações \\
\hline $\begin{array}{l}\text { CASCATA RADDATZ } \\
\text { COM. ROLF PACHALY }\end{array}$ & $\begin{array}{l}\text { Proteção Fontes / Construção de } \\
\text { pocilgas. } \\
\text { Construção de Cisterna. }\end{array}$ & $\begin{array}{l}\text { Foi realizada a proteção das fontes, } \\
\text { mas as demais ações ainda não } \\
\text { obtiveram êxito por dificuldade de } \\
\text { reunir a comunidade para um } \\
\text { mutirão. }\end{array}$ \\
\hline COM. BTO GONÇALVES & Sumidouro. & $\begin{array}{l}\begin{array}{l}\text { Apoio do poder público com } \\
\text { máquinas. }\end{array} \\
\end{array}$ \\
\hline E. STO ANTONIO & $\begin{array}{l}\text { Lixeiras na Comunidade. } \\
\text { Melhoria nos depósitos de água. }\end{array}$ & $\begin{array}{l}\text { As lixeiras estão colocadas, mas a } \\
\text { qualificação dos depósitos não } \\
\text { precisará ser feita devido à nova } \\
\text { estrutura de abastecimento da } \\
\text { comunidade (rede de água } \\
\text { comunitária) que estará concluída em } \\
\text { julho e ofertará água clorada. }\end{array}$ \\
\hline SOCIEDADE FARROUPILHA & $\begin{array}{l}\text { Fossa, Sumidouro - Lixeiras no } \\
\text { Pavilhão }\end{array}$ & Falta de organização comunitária. \\
\hline COMUNIDADE SÃO MARCOS & $\begin{array}{l}\text { Lixeiras no pavilhão e Cemitério } \\
\text { Destino das águas servidas }\end{array}$ & $\begin{array}{l}\text { Falta de diálogo entre a liderança que } \\
\text { assumiu o compromisso e as } \\
\text { lideranças que foram eleitas } \\
\text { posteriormente. }\end{array}$ \\
\hline COMUNIDADE SANTA LUZIA & Lixeiras no pavilhão e Cemitério. & $\begin{array}{l}\text { Falta de diálogo entre as lideranças e } \\
\text { organização efetiva para a conclusão } \\
\text { da ação. Falta de recursos } \\
\text { financeiros. }\end{array}$ \\
\hline SOCIEDADE PORTO ALVES & $\begin{array}{l}\text { Colocação de lixeiras e destino dos } \\
\text { esgotos geral. }\end{array}$ & Falta de diálogo entre as lideranças. \\
\hline $\begin{array}{l}\text { GRUPO TURISMO EMATER } \\
\text { E. SANTOS DUMONT } \\
\text { E. WILLY ROOS } \\
\text { E. D. PEDRO II } \\
\text { CONDEMA/GRUPO CERRO CHATO }\end{array}$ & Arborização urbana. & $\begin{array}{l}\text { O Início do projeto já aconteceu, } \\
\text { sendo que a idéia motivou a } \\
\text { construção de um Plano de } \\
\text { Arborização Municipal. }\end{array}$ \\
\hline
\end{tabular}

Quadro 2. Justificativas quanto a não realização das ações. 
Monografias Ambientais

(e-ISSN: 2236-1308)

REMOANFSM

\begin{tabular}{|c|c|c|}
\hline $\begin{array}{l}\text { SEJAMIGO } \\
\text { ATRA/ GRUPO ESPERANÇA } \\
\text { GRUPO RENASCER } \\
\text { COMUNIDADE CONGREGACIONAL }\end{array}$ & $\begin{array}{l}\text { Sumidouro na Com. São José - R. } \\
\text { Pinhal. } \\
\text { Embelezamento do Cemitério do } \\
\text { Rincão do Pinhal. } \\
\text { Colocação de Lixeiras na comunidade } \\
\text { São José. }\end{array}$ & $\begin{array}{l}\text { Falta de apoio do poder público no } \\
\text { empréstimo de máquinas para o } \\
\text { projeto de implantação do } \\
\text { sumidouro. As lixeiras já foram } \\
\text { colocadas e o embelezamento } \\
\text { realizado em parte. }\end{array}$ \\
\hline $\begin{array}{l}\text { E. OLAVO BILAC } \\
\text { GRUPO SOL NASCENTE } \\
\text { COMUNIDADE EVANGÉLICA }\end{array}$ & $\begin{array}{l}\text { - Construção de depósito de lixo na } \\
\text { escola e comunidade para posterior } \\
\text { coleta. } \\
\text { - Canalizar esgotos. } \\
\text { - Manejo da criação de suínos em } \\
\text { propriedade ao lado da escola }\end{array}$ & $\begin{array}{l}\text { O local de armazenagem de lixo na } \\
\text { escola está pronto. Os demais } \\
\text { demandam ajuda de máquinas } \\
\text { públicas e o manejo da criação de } \\
\text { suínos depende também da } \\
\text { motivação do proprietário e vizinho } \\
\text { da escola. }\end{array}$ \\
\hline $\begin{array}{l}\text { SOCIEDADE UNIÃO/GRUPO SEMPRE } \\
\text { AMIGAS }\end{array}$ & Lixeiras no Cemitério e na Sociedade & $\begin{array}{l}\text { A colocação de lixeiras no cemitério } \\
\text { está concluída, na sociedade ainda } \\
\text { não, por falta de atitude das } \\
\text { lideranças. }\end{array}$ \\
\hline
\end{tabular}

Quadro 2. Justificativas quanto a não realização das ações (continuação).

Apesar do espaço disponibilizado, a grande maioria não mostrou interesse em apresentar os resultados no Seminário do Meio Ambiente, ficando então acordado que a divulgação dos mesmos seria na imprensa escrita local, no mês de outubro, devido à comemoração da Semana Interamericana da Água. Somente a comunidade São José, de Rincão do Pinhal, e o grupo Força Jovem, que sediou o Seminário, apresentaram as ações concluídas aos participantes.

Como forma de motivar às lideranças à ação, em julho e agosto foram veiculadas notícias no programa de rádio da Prefeitura de Agudo, que acontece diariamente na Rádio Agudo, pedindo que entrassem em contato com o Departamento de Meio Ambiente caso estivesse havendo alguma dificuldade na execução das atividades, e àqueles que já estivessem concluído, que enviassem fotos dos trabalhos.

Em outubro foi realizada a última visita para o levantamento da conclusão das ações. No Quadro 3 descreve-se a situação final e as percepções das lideranças quanto às dificuldades, auxílio da comunidade e satisfação pessoal na implementação das ações.

\begin{tabular}{|l|l|}
\hline ORGANIZAÇÕES/Situação final das ações & $\begin{array}{l}\text { Percepções quanto às dificuldades, auxílio da comunidade e } \\
\text { satisfação pessoal na implementação das ações. }\end{array}$ \\
\hline $\begin{array}{l}\text { CASCATA RADDATZ } \\
\text { - COM. ROLF PACHALY } \\
\text { - Construção de pocilgas (não concluída) }\end{array}$ & $\begin{array}{l}\text { A proteção das fontes foi realizada na propriedade particular da } \\
\text { Cascata Raddatz. As demais ações não tiveram interesse da } \\
\text { comunidade na implementação. A liderança sente-se frustrada } \\
\text { em perceber o desinteresse dos demais membros da } \\
\text { comunidade. }\end{array}$ \\
\hline COM. BTO GONÇALVES & $\begin{array}{l}\text { A comunidade é organizada e "pega junto" quando precisa. Nesse } \\
\text { caso o que faltou foi o apoio da Secretaria de Obras do Município, } \\
\text { que prometeu máquinas para abertura do buraco para a fossa e } \\
\text { sumidouro, e não cumpriu. } \\
\text { A sensação é de frustração, pois foram inúmeras as vezes que a } \\
\text { máquina foi solicitada. }\end{array}$ \\
\hline
\end{tabular}

Quadro 3- Percepções quanto às dificuldades, auxílio da comunidade e satisfação pessoal na implementação das ações. 
Monografias Ambientais

\begin{tabular}{|c|c|}
\hline Lixeiras na Comunidade (concluída) & $\begin{array}{l}\text { Não houve dificuldade em implantar as lixeiras. Houve auxílio } \\
\text { financeiro do Grupo de Jovens, Clube de Mães, Comunidade } \\
\text { Católica e escola. } \\
\text { A ação gerou organização principalmente nos eventos, e as } \\
\text { lideranças entendem que é o ponto inicial para mudança de uma } \\
\text { questão cultural de uso de lixeiras também nos bailes. }\end{array}$ \\
\hline $\begin{array}{l}\text { SOCIEDADE FARROUPILHA } \\
\begin{array}{l}\text { Fossa, Sumidouro e Lixeiras no Pavilhão } \\
\text { (concluída) }\end{array}\end{array}$ & $\begin{array}{l}\text { "A dificuldade foi iniciar as obras. Os integrantes da diretoria } \\
\text { moram longe. Mas a diretoria é unida e foi rápida a conclusão. A } \\
\text { sensação é de dever cumprido. " }\end{array}$ \\
\hline $\begin{array}{l}\text { COMUNIDADE SÃO MARCOS } \\
\text { - Lixeiras no pavilhão e Cemitério (concluído) } \\
\text { - Destino das águas servidas (não concluído) }\end{array}$ & $\begin{array}{l}\text { A compra das lixeiras e o plantio das mudas foi algo rápido, que } \\
\text { não demandou envolvimento de muitas pessoas. Já o destino das } \\
\text { águas servidas está sendo difícil começar. }\end{array}$ \\
\hline $\begin{array}{l}\text { COMUNIDADE SANTA LUZIA } \\
\text { - Lixeiras no pavilhão (não concluído) } \\
\text { - Lixeiras no Cemitério (concluído) }\end{array}$ & $\begin{array}{l}\text { A comunidade é pequena e passava por dificuldades financeiras. } \\
\text { Foi utilizada uma antiga caixa d'água como alternativa de lixeira } \\
\text { no cemitério (que é pequeno e comporta essa prática). No } \\
\text { pavilhão serão adquiridas lixeiras após a chegada de uma verba } \\
\text { de um deputado da região. }\end{array}$ \\
\hline $\begin{array}{l}\text { SOCIEDADE PORTO ALVES } \\
\text { Colocação de lixeiras e destino dos esgotos geral } \\
\text { (não concluída). }\end{array}$ & $\begin{array}{l}\text { Não foi realizado nada por falta de tempo e interesse. Os } \\
\text { representantes não tinham a representatividade comunitária de } \\
\text { tomada de decisão, e quando repassaram a idéia não houve } \\
\text { motivação suficiente para a implementação. As atividades no } \\
\text { referido local de encontro (Sociedade Porto Alves) estão cada vez } \\
\text { mais escassas, fazendo com que se tenha pouco contato com a } \\
\text { problemática descrita. }\end{array}$ \\
\hline $\begin{array}{l}\text { GRUPO TURISMO EMATER } \\
\text { E. SANTOS DUMONT } \\
\text { E. WILLY ROOS } \\
\text { E. D. PEDRO II } \\
\text { CONDEMA/GRUPO CERRO CHATO } \\
\text { Arborização urbana (concluída parcialmente) }\end{array}$ & $\begin{array}{l}\text { Algumas lideranças "perderam-se" pelo caminho, mas a } \\
\text { articulação com o Poder Público gerou uma garantia de } \\
\text { continuidade do projeto e um envolvimento maior de } \\
\text { profissionais técnicos no mesmo. (ANEXO D) }\end{array}$ \\
\hline 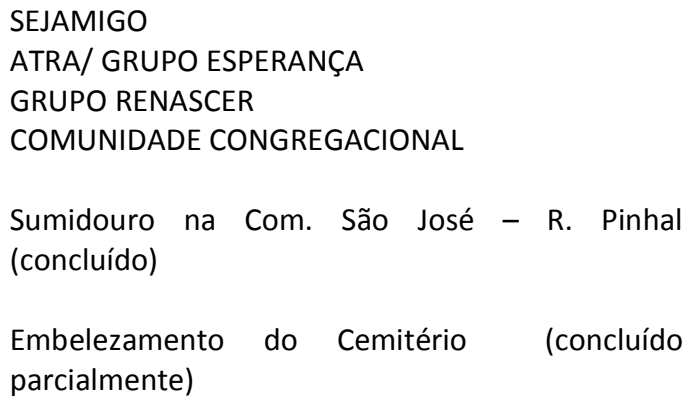 & $\begin{array}{l}\text { Não houveram grandes dificuldades, só a questão de tirar tempo } \\
\text { para fazer. O envolvimento das demais lideranças foi muito } \\
\text { positivo, mas é necessário ter sempre quem realmente "puxa à } \\
\text { frente". A satisfação é grande em ver o trabalho concluído. No } \\
\text { entanto, após a conclusão do sumidouro, uma empreiteira que } \\
\text { fará a nova escola da comunidade, ao lado do pavilhão, destruiu a } \\
\text { mesma e canalizou o sistema para uma nova estrutura que } \\
\text { atenderá a escola e a comunidade. Apesar disso, houve } \\
\text { desmotivação de quem trabalhou, pois a sensação de "serviço } \\
\text { botado fora" é que fica. }\end{array}$ \\
\hline $\begin{array}{l}\text { Colocação de Lixeiras - combate a queimada de } \\
\text { lixo (concluída) }\end{array}$ & $\begin{array}{l}\text { Sobre o embelezamento do cemitério, a comunidade iniciou o } \\
\text { plantio de palmeiras e contratou uma firma local para projetar e } \\
\text { executar o ajardinamento do mesmo, sendo que isso ainda não } \\
\text { foi concluído. }\end{array}$ \\
\hline
\end{tabular}

Quadro 3- Percepções quanto às dificuldades, auxílio da comunidade e satisfação pessoal na implementação das ações (continuação). 


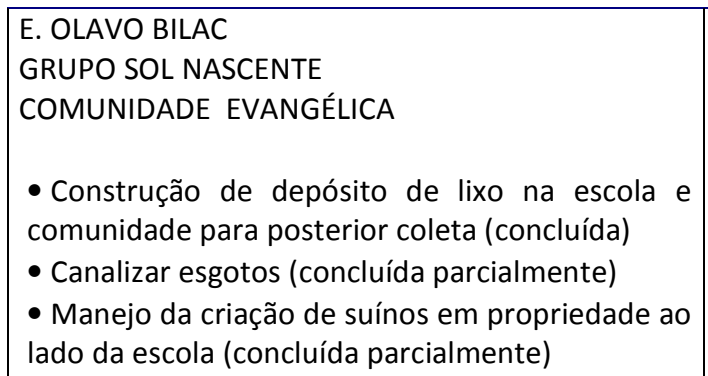

Quadro 3- Percepções quanto às dificuldades, auxílio da comunidade e satisfação pessoal na implementação das ações (continuação).

Analisando de forma quantitativa, das 26 (vinte e seis) ações propostas, 15 (quinze) foram concluídas, perfazendo um percentual de aproximadamente $57 \%$. Realizadas parcialmente foram 04 (quatro) ações, cujo percentual atinge $15 \%$ do total, mas seus encaminhamentos levam a crer que sua conclusão acontecerá a contento (arborização urbana e embelezamento do cemitério do Rincão do Pinhal),. Não foram realizadas $28 \%$ das ações, ou seja, o número de 07 (sete). No entanto, como não havia sido definida uma meta quantitativa, o resultado qualitativo da sensibilização das lideranças é o parâmetro que se utilizou para concluir e de certa forma avaliar a proposição do trabalho de sensibilização e implantação de ações ambientais nas comunidades agudenses.

Por ser algo intrínseco e extremamente individual, o resultado de uma prática de sensibilização para gerar motivação a uma ação difícil de ser medido. Verifica-se que 57 \% das ações propostas tiveram êxito, pode-se considerar que o objetivo foi alcançado. No entanto, como muitas das ações dependiam do envolvimento de outros indivíduos, que não estiveram diretamente ligados ao projeto, recebendo a mensagem inicial que tinha o objetivo de justamente 
despertar essa motivação, não se pode afirmar com certeza que o trabalho tenha sido em vão ou negativo para algumas lideranças.

A conscientização da importância das ações comunitárias como exemplo aos demais integrantes de uma comunidade, respeitando o meio ambiente e procurando sempre melhorar a qualidade de vida dos envolvidos, pode ser algo que pulsa nas mentes dessas lideranças, mas que talvez pelas circunstâncias não pode ainda ser concretizada na prática. Somente um acompanhamento dessas comunidades e a continuidade de ações de sensibilização, poderão nos dizer se a semente lançada dará frutos.

Com os resultados obtidos percebe-se a importância dos comprometimentos individuais com o que se propõe. Inúmeras justificativas são dadas, mas efetivamente a responsabilidade pela não conclusão dos trabalhos é basicamente reflexo da morosidade ou da falta de pró-atividade das lideranças, pois após sua conclusão, os depoimentos demonstram que não houve dificuldades nem demora na execução. No entanto não se pode excluir a responsabilidade do Poder Público com os serviços de máquina direcionados às ações comunitárias, cuja demora interferiu decisivamente na conclusão positiva de alguns dos projetos e na não realização de outros. Destacaram-se as ações pessoais, cujos atores são pessoas que demonstram ter consciência e identificação com a causa ambiental, fazendo diferença no contexto comunitário e regional em que estão inseridos, e conseqüentemente no sucesso deste projeto.

Despertar lideranças para a constante educação ambiental e ainda de forma que estas possam interferir junto às famílias de sua comunidade, é meta audaciosa junto a uma cultura individualista como a de Agudo. Percebe-se nas comunidades, uma cultura centralizadora na administração das diretorias, o que dificulta a renovação de lideranças, já que as pessoas fogem desse modelo de que "quem é presidente ou da diretoria é quem faz tudo". Nesse contexto é importante também investir na formação dos líderes para aos poucos quebrar esse paradigma, objetivando o "aprender a ser líder", valorizando seu estilo pessoal, mas aprendendo a dividir tarefas para que haja parceria para as ações que são para o bem de todos.

\section{CONCLUSÃO}

Todos os atores envolvidos em um projeto de educação ambiental aprendem e ensinam concomitantemente se possuírem humildade e abertura para tal. As realidades vivenciadas e os momentos de trocas de experiência são riquíssimos e podem contribuir para aumentar o nível de consciência de quem estiver no processo.

Como em se tratando de educação ambiental os resultados nem sempre são imediatos, conclui-se que o objetivo de sensibilizar os agentes multiplicadores para o desenvolvimento de ações comunitárias para melhoria da qualidade ambiental local foi alcançado. A partir de um diagnóstico prévio de problemas ambientais, afim de motivar a ação sobre os mesmos na busca de sua resolutividade com ações conjuntas em suas comunidades de atuação, podemos perceber resultados significativos como arborizações e embelezamentos, ajustes na destinação de águas servidas e esgoto cloacal de centros comunitários rurais, implantação de lixeiras, construção de fontes drenadas, entre outras. Desta forma, os envolvidos agiram como multiplicadores em educação ambiental no nível de suas comunidades de atuação. 
O levantamento dos resultados e sua divulgação também aconteceram a contento. As lideranças colocaram-se sempre a disposição para fornecer informações sobre o andamento dos projetos e as causas de possíveis demoras ou falta de conclusão, bem como a adesão por parte dos integrantes das comunidades. Houve também compreensão e apoio na divulgação dos resultados na imprensa falada e escrita, por meio de fotos, o que promove a visibilidade das ações comunitárias e conseqüentemente a motivação das pessoas que participaram da execução dos projetos.

Finalmente, espera-se que se consiga manter viva a chama que motiva cada liderança, cada ator envolvido no processo, a dar continuidade no seu trabalho ambiental e comunitário, no intuito de que ações como as que foram desenvolvidas sejam exemplo para as presentes e futuras gerações.

\section{BIBLIOGRAFIA}

BERNARDINI, C. Chamamento e relatório - campanha lâmpadas fluorescentes. Departamento de Meio Ambiente da Prefeitura de Agudo/RS, 2009.

Relatório Campanha Pneus. Departamento de Meio Ambiente da Prefeitura de Agudo/RS, 2006.

Agudo/RS, 2007.

Relatório da II Operação Agudo Limpo. Departamento de Meio Ambiente da Prefeitura de Agudo/RS, 2006.

Relatório do Projeto “Operação Agudo Limpo”. Departamento de Meio Ambiente da Prefeitura de Relatório Fórum da Água. Departamento de Meio Ambiente da Prefeitura de Agudo/RS, 2006.

. III Operação Agudo Limpo. Departamento de Meio Ambiente da Prefeitura de Agudo/RS, 2008.

BRASIL. Constituição da República Federativa do Brasil de 1988 Disponível em: http://www.planalto.gov.br/ccivil 03/constituicao/constitui\%C3\%A7ao.htm. Acesso em: 17 mai.2010.

. Lei $\mathbf{N}^{\circ}$ 9.795, de 27 de abril de 1999. Dispõe sobre a educação ambiental, institui a Política Nacional de Educação Ambiental e dá outras providências. Disponível em: http://www.planalto.gov.br/ccivil 03/Leis/L9795.htm Acesso em 17 mai.2010.

DECLARAÇÃO DE TBILISI (1977). Disponível em: <http://translate.google.com.br/translate?hl=ptR\&langpair=en\%7Cpt\&u=http://www.

gdrc.org/uem/ee/tbilisi.html>. Acesso em: 23 set.2010.

DIAS, G. F. Educação Ambiental: princípios e práticas. São Paulo, Gaia, 2004

DICIONÁRIO AURÉLIO. Disponível em: <http://www.dicionariodoaurelio. com/Sensibilizar>. Acesso em 12 ago.2010.

DICIONÁRIO AURÉLIO. Disponível em: <http://www.dicionariodoaurelio. com/Consciencia>. Acesso em: 12 ago.2010.

KNAPIK, J. Gestão de Pessoas e Talentos. Curitiba: Ibpex, 2006. 
MEDINA, N. M. Antecedentes Históricos: Conferências Internacionais, in Educação Ambiental: Curso básico à distância: documentos e legislação da educação ambiental. Ana Lúcia Tostes de Aquino Leite e Naná Mininni-Medina (Coord). Brasília: MMA. 2001. 5v., 2ª edição ampliada.

MÜLLER, J. Educação Ambiental: diretrizes para a prática pedagógica. Porto Alegre: FAMURS, 2000.

MÜLLER, J. Meio Ambiente na Administração Municipal. Diretrizes para Gestão Ambiental Municipal. Porto Alegre: FAMURS, 2001, 2a edição.

PERIARD,G. FERRAMENTA 5W2H. Disponível em:

<http://www.sobreadministracao.com/o-que-e-o-5w2h-e-como-ele-e-utilizado/> Acesso em: 05 mai. 2010.

ROSA, A.C.M. As grandes linhas e orientações metodológicas da Educação Ambiental, in Educação Ambiental: Curso básico à distância: Educação e Educação Ambiental I. Ana Lúcia Tostes de Aquino Leite e Naná Mininni-Medina (Coord). Brasília: MMA. 2001. 5v., 2ª edição ampliada.

SILVA, E.L.; MENEZES, E.M. Metodologia da pesquisa e elaboração de dissertação.Florianópolis: Laboratório de Ensino a Distância da UFSC, $2001 . \quad$ Disponível em: http://projetos.inf.ufsc.br/arquivos/Metodologia\%20da\%20Pesquisa\%203a\%20edicao.pdf> Acesso em: 19 out.2010.

UNIVERSIDADE FEDERAL DE SANTA MARIA. Estrutura e Apresentação de Monografias, Dissertações e Teses: MDT. Santa Maria: Ed. da UFSM, 2006. 